\title{
AVALIAÇÃO DA QUALIDADE MICROBIOLÓGICA DE OVO INTEGRAL PASTEURIZADO PRODUZIDO COM E SEM A ETAPA DE LAVAGEM NO PROCESSAMENTO
}

\author{
Lina Casale ARAGON-ALEGRO", Kátia Leani de Oliveira SOUZA", \\ Paulo de Souza COSTA SOBRINHO', Mariza LANDGRAF², Maria Teresa DESTRO
}

\begin{abstract}
RESUMO
Microrganismos patogênicos podem contaminar ovos em diferentes estágios do processamento. Na tentativa de reduzir problemas decorrentes dessa contaminação por microrganismos patogênicos e/ou deteriorantes, os ovos são submetidos a processos como lavagem da casca e pasteurização. Vários estudos mostraram que alguns agentes químicos utilizados nessa lavagem podem causar danos físicos ao produto, facilitando a entrada de microrganismos através da casca. O nosso objetivo foi avaliar a eficiência da lavagem dos ovos, anteriormente à quebra, na redução da contaminação de ovo integral líquido. Foram colhidas amostras de ovo integral em 3 pontos da linha de produção, provenientes de ovos lavados e não lavados. Foram feitas pesquisa de Salmonella sp e enumeração de S. aureus, L. monocytogenes e bactérias aeróbias. Os resultados foram analisados no nível de significância de $5 \%$ e pôde-se concluir que o emprego, ou não, da etapa de lavagem não tem influência na qualidade microbiológica do produto final.

Palavras-chave: ovos; lavagem; qualidade microbiológica.
\end{abstract}

\section{SUMMARY}

INFLUENCE OF WASHING IN THE MICROBIAL QUALITY OF PASTEURIZED EGG. Pathogenic microrganisms can contaminate eggs at different stages of processing. In an attempt to reduce problems resulting from contamination by pathogenic and/or deteriorating microrganisms, the eggs are submitted to processes such as washing the egg shell and pasteurization. Some studies have shown that chemical agents used to wash the egg shells can cause physical damage to the product, facilitating the entry of microrganisms through the shell. Our aim was to evaluate the efficiency of washing the eggs, prior to breaking them, to reduce the contamination of whole liquid egg (intended for pasteurization). Samples of whole eggs from both washed and unwashed eggs were taken at three points in the production line. Tests for Salmonella sp and enumeration of S. aureus, L. monocytogenes and aerobic bacteria were carried out. The results were analysed at the significant level of $5 \%$ and it was concluded that whether the eggs were washed or not had no influence on the microbiological quality of the final product.

Keywords: eggs; washing; microbiological quality.

\section{1 - INTRODUÇÃO}

O ovo é utilizado com muita freqüência pela população brasileira pois, além de apresentar preços acessiveis, faz parte do seu hábito alimentar. Trata-se de um alimento fonte de proteínas de alto valor biológico e sua gema é rica em vitamina A [21].

Na indústria de alimentos, o ovo - pasteurizado, congelado ou desidratado - é utilizado preferencialmente ao ovo em casca, pois, além do sabor, cor, valor nutritivo e propriedades funcionais serem comparáveis aos do ovo in natura, apresenta vantagens operacionais, como melhor qualidade, estabilidade e uniformidade, economia de mão-de-obra, menor espaço para armazenamento e facilidade para medir as porções [2]. O ovo líquido é utilizado na fabricação de vários alimentos como bolos, merengues, produtos de confeitaria, embutidos, etc. [3].

Recebido para publicação em 14/06/2005. Aceito para publicação em 11/08/2005(001552).

"Departamento de Alimentos e Nutrição Experimental, Faculdade de Ciências Farmacêuticas, Universidade de São Paulo. Endereço: Av. Prof. Lineu Prestes, 580, Bloco 14, Cidade Universitária, CEP: O5508900, São Paulo-SP.

A quem a correspondência deve ser enviada.
Não há dados oficiais sobre a produção brasileira de ovo pasteurizado, porém, segundo o Ministério da Agricultura, Pecuária e Abastecimento [5], no ano de 2003 foram produzidas 40.112 caixas com 30 dúzias de ovos cada, no Brasil.

A maioria dos ovos apresenta pouca ou nenhuma contaminação no momento da postura, e a contaminação ocorre geralmente após a oviposição $[10,19]$. Entre os meios prováveis de sua contaminação estão o contato com as fezes das aves no momento da postura e a contaminação, por penetração do microrganismo, através de rachaduras microscópicas e/ou dos poros da casca após a lavagem [12]. Ovos podem também se contaminar via transovariana. Neste caso, a contaminação está localizada na gema e os processos convencionais de desinfecção dos ovos não são eficientes [16]. Entre os gêneros bacterianos mais comumente envolvidos na deterioração desse alimento estão Pseudomonas, Acinetobacter, Proteus, Aeromonas, Alcaligenes, Escherichia, Micrococcus, Serratia, Enterobacter e Flavobacterium. Os principais patógenos associados são Salmonella, Staphylococcus, Campylobacter jejuni, Listeria monocytogenes e Yersinia enterocolitica [20].

A contaminação externa da casca do ovo é importante para determinação de sua vida-de-prateleira e para a segurança dos consumidores [22]. Na tentativa de reduzir problemas decorrentes da contaminação por microrganismos patogênicos e/ou deteriorantes, os ovos são 
submetidos a processos como a lavagem da casca e a pasteurização. Recentemente, vários estudos têm mostrado que alguns agentes químicos utilizados na lavagem dos ovos podem causar danos fisicos ao produto, facilitando, inclusive, a entrada de bactérias patogênicas através da casca [9].

Assim, o nosso objetivo com este trabalho foi avaliar a eficiência da lavagem dos ovos, anteriormente à quebra, na redução da contaminação de ovo integral líquido por Listeria monocytogenes, Staphylococcus aureus, Salmonella sp e seu efeito sobre a população de microrganismos aeróbios.

\section{2 - MATERIAL E MÉTODOS}

\section{1 - Material}

Foram colhidas amostras de ovo integral em 3 pontos distintos da linha de produção (máquina de quebra MQ, tanque de estocagem - TE e após pasteurização PA), provenientes de ovos lavados com solução clorada (200 ppm) e não lavados.

A cada dia de amostragem, 3 amostras foram coletadas em intervalos de 30 minutos, aproximadamente 2h30min. após o início das operações da linha, em cada um dos pontos de coleta. As amostras foram coletadas por funcionários da própria empresa, colocadas em embalagens plásticas estéreis de 1 litro e encaminhadas ao Laboratório de Microbiologia de Alimentos - FCF - USP, acondicionadas em caixa isotérmica contendo gelo. Este processo foi repetido 3 vezes.

\section{2 - Métodos}

\subsection{1 - Análises microbiológicas}

Todos os meios de cultura utilizados, quando não especificados, pertenciam à marca Oxoid (Basingstoke, GB).

\section{- Pesquisa de Salmonella $\mathrm{sp}$ [1]}

Foram pesados assepticamente, em embalagem plástica estéril, $25 \mathrm{~g}$ de cada amostra que foram homogeneizados com $225 \mathrm{~mL}$ de caldo soja tripticase (TSB) adicionado de $35 \mathrm{mg} / \mathrm{L}$ de sulfato ferroso (Baker Chemical). A mistura foi mantida durante uma hora em temperatura ambiente e o $\mathrm{pH}$ foi verificado e corrigido para $6,8+0,2$. $\mathrm{O}$ caldo foi incubado a $35^{\circ} \mathrm{C}$ por $24 \mathrm{~h}$ e, após esse tempo, aliquotas foram transferidas para caldo RappaportVassiliadis (RV) e para caldo Tetrationato (TT). O caldo RV foi incubado a $42^{\circ} \mathrm{C}$ e o TT, a $35^{\circ} \mathrm{C}$, ambos por $24 \mathrm{~h}$. Foi feita a semeadura superficial a partir de cada caldo nos ágares Rambach (Merck) e Hektoen enteric (HE) e essas placas foram incubadas a $35^{\circ} \mathrm{C}$ por $24 \mathrm{~h}$. Quando houve colônias características, foram realizados testes bioquímicos com utilização dos ágares Ferro Triplice Açúcar (TSI) e Lisina Ferro (LIA) e sorologia (soro polivalente Probac).
- $\quad$ Enumeração de S. aureus [4] e de bactérias aeróbias [13]

Foram pesados assepticamente, em embalagem plástica estéril, $25 \mathrm{~g}$ de cada amostra que foram homogeneizados com $225 \mathrm{~mL}$ de solução de peptona a $0,1 \%$. Para a enumeração de $S$. aureus foram semeadas aliquotas de 0,$3 ; 0,3 ; 0,3$ e 0,1 mL em ágar Baird-Parker e as placas foram incubadas a $37^{\circ} \mathrm{C} / 48 \mathrm{~h}$. As colônias características foram contadas e, de cada placa, foram retiradas 5 , que foram testadas quanto à produção de coagulase. Para a enumeração de bactérias aeróbias as diluições decimais foram semeadas em ágar para contagem padrão (PCA) e as placas foram incubadas a $25^{\circ} \mathrm{C} / 48 \mathrm{~h}$. Após esse período, foi realizada a enumeração das colônias.

- Enumeração de L. monocytogenes [18]

Foram pesados assepticamente, em embalagem plástica estéril, $25 \mathrm{~g}$ de cada amostra que foram homogeneizados com $100 \mathrm{~mL}$ de solução de peptona a $1 \%$. Foram semeadas superficialmente, com auxílio de alça de Drigalski, 3 placas de ágar Oxford e 3 placas de ágar Palcam com aliquotas de $0,33 \mathrm{~mL}$ do caldo. As placas foram incubadas a $35^{\circ} \mathrm{C} / 48 \mathrm{~h}$. As colônias características foram purificadas e identificadas através de testes bioquímicos como produção de catalase e fermentação de carboidratos (xilose, dextrose, ramnose e manitol) e teste de motilidade.

\subsection{2 - Análises estatísticas}

As populações de L. monocytogenes, de S. aureus e de bactérias aeróbias obtidas foram calculadas para cada uma das 3 amostras coletadas por dia, expressas em UFC/g e as populações médias de cada dia calculadas. As populações médias foram comparadas empregandose $\mathrm{o}$ teste $\mathrm{t}$, no nível de significância de $5 \%$. Para Salmonella, o resultado foi expresso como presença/ausência em $25 \mathrm{~g}$ e a proporção de igualdade dos resultados, avaliada empregando-se o teste de Exatidão de Fisher, também no nivel de 5\% de significância [17].

\section{3 - RESULTADOS E DISCUSSÃO}

Nas Tabelas 1 e 2 encontram-se os resultados obtidos para cada ponto de coleta para cada uma das repetições realizadas. Os resultados apresentados são a média das 3 amostras examinadas por dia de coleta. Para Salmonella, considerou-se como ausência quando todas as 3 amostras examinadas no dia foram negativas para o patógeno; e presença, quando pelo menos 1 amostra, dentre as 3 examinadas, foi positiva.

Pode-se observar que, nem Listeria sp nem estafilococos produtores de coagulase foram detectados nas amostras examinadas, tanto nas produzidas com ovos lavados, quanto não lavados, independentemente do ponto de coleta (Tabelas 1 e 2).

Ao contrário do que se podia esperar, o emprego da lavagem em solução clorada (200ppm) não produziu uma redução estatisticamente significativa $(p>0,05)$ na popu- 
Lavagem e qualidade microbiológica do ovo integral pasteurizado, Aragon-Alegro et al.

TABELA 1 - Média dos resultados obtidos para o total de amostras produzidas com ovos lavados

\begin{tabular}{|c|c|c|c|c|c|}
\hline Ponto de coleta & Amostragem & $\begin{array}{l}\text { Salmonella sp } \\
\text { (em 25g) }\end{array}$ & L. monocytogenes (UFC/g) & $\begin{array}{l}\text { Bactérias aeróbias } \\
\text { mesófilas (UFC/g) }\end{array}$ & $\begin{array}{l}\text { S. aureus } \\
\text { (UFC/g) }\end{array}$ \\
\hline \multirow[t]{3}{*}{ MQ } & I & presença & $<5$ & $8,4 \times 10^{4}$ & $<100$ \\
\hline & II & ausência & $<5$ & $1,7 \times 10^{3}$ & $<100$ \\
\hline & III & ausência & $<5$ & $3,6 \times 10^{5}$ & $<100$ \\
\hline \multirow[t]{3}{*}{$\mathrm{TE}$} & I & presença & $<5$ & $1,6 \times 10^{5}$ & $<100$ \\
\hline & II & presença & $<5$ & $4,6 \times 10^{3}$ & $<100$ \\
\hline & III & ausência & $<5$ & $2,5 \times 10^{5}$ & $<100$ \\
\hline \multirow[t]{3}{*}{ PA } & I & ausência & $<5$ & $3,1 \times 10^{2}$ & $<10$ \\
\hline & II & ausência & $<5$ & $<10$ & $<10$ \\
\hline & III & ausência & $<5$ & $1,4 \times 10^{2}$ & $<10$ \\
\hline
\end{tabular}

$\mathrm{MQ}=$ máquina de quebra; $\mathrm{TE}=$ tanque de estocagem; $\mathrm{PA}=$ após pasteurizaçăo

TABELA 2 - Média dos resultados obtidos para o total de amostras produzidas com ovos não lavados

\begin{tabular}{|c|c|c|c|c|c|}
\hline Ponto de coleta & Amostragem & $\begin{array}{c}\text { Salmonella sp } \\
\text { (em 25g) }\end{array}$ & L. monocytogenes (UFC/g) & $\begin{array}{l}\text { Bactérias aeróbias } \\
\text { mesófilas (UFC/g) }\end{array}$ & $\begin{array}{l}\text { S. aureus } \\
\text { (UFC/g) }\end{array}$ \\
\hline \multirow[t]{3}{*}{ MQ } & $\bar{I}$ & ausência & $<5$ & $2,4 \times 10^{5}$ & $<100$ \\
\hline & II & ausência & $<5$ & $1,13 \times 10^{3}$ & $<100$ \\
\hline & III & presença & $<5$ & $2,3 \times 10^{5}$ & $<100$ \\
\hline \multirow[t]{3}{*}{$\mathrm{TE}$} & I & presença & $<5$ & $1,2 \times 10^{5}$ & $<100$ \\
\hline & II & ausência & $<5$ & $4,6 \times 10^{3}$ & $<100$ \\
\hline & III & ausência & $<5$ & $1,8 \times 10^{5}$ & $<100$ \\
\hline \multirow[t]{3}{*}{$\mathrm{PA}$} & I & ausência & $<5$ & $4,6 \times 10^{2}$ & $<10$ \\
\hline & II & ausência & $<5$ & $<10$ & $<10$ \\
\hline & III & ausência & $<5$ & $1,93 \times 10^{2}$ & $<10$ \\
\hline
\end{tabular}

$\mathrm{MQ}=$ máquina de quebra; $\mathrm{TE}$ = tanque de estocagem; $\mathrm{PA}=$ após pasteurização.

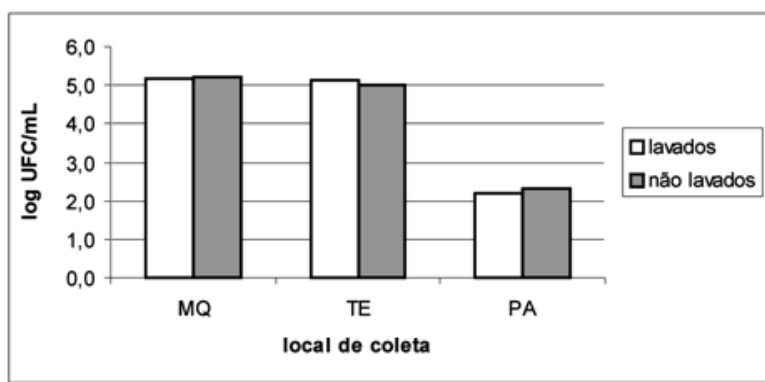

FIGURA 1 - Médias das populações de bactérias aeróbias mesófilas, em ovo integral proveniente de ovos lavados e não lavados, nos três diferentes pontos de coleta $(\mathrm{MQ}=$ máquina de quebra; TE = tanque de estocagem; $\mathrm{PA}$ = após pasteurização)

lação de microrganismos aeróbios mesófilos. Isto pode ser observado na Figura 1, onde as populações médias deste grupo de microrganismo encontradas nas etapas MQ e TE são bastante semelhantes tanto quando se empregou ovos lavados como sem lavar.

Por outro lado, após a pasteurização, houve redução na população dos aeróbios mesófilos, indicando sua eficiência, mas os resultados obtidos, tanto com os ovos lavados como sem lavar, também não apresentaram diferença estatisticamente significativa (Figura 1).

Também não se observou diferença estatisticamente significativa para a proporção de amostras positivas obtidas para Salmonella no produto anteriormente à pasteurização (Tabelas 1 e 2). O importante é que este patógeno foi eliminado após o processo de pasteurização.

O emprego ou não da lavagem de ovos, anteriormente à quebra, tem sido motivo de discussão. No Brasil, o
Regulamento da Inspeção Industrial e Sanitária de Produtos de Origem Animal (RIISPOA) [6] refere que ovos destinados a industrialização devem ser previamente lavados, sendo que é recomendada a utilização de compostos de cloro em niveis inferiores a 50ppm na água de lavagem. Vários países, como Estados Unidos, Austrália e Japão já adotaram o processo de lavagem de ovos. $\mathrm{Na}$ União Européia a lavagem de ovos é legalmente permitida para ovos do tipo B, utilizado para processamento, porém, nenhuma orientação foi emitida pela Comissão Européia para descrever como isso pode garantir a inocuidade [9].

Vários tipos de microrganismos podem ser encontrados na casca de ovos, e eles variam de acordo com as circunstâncias, sendo os mais comuns encontrados também no ar, solo e água [14]. Além disto, ovos de galinha podem servir como veículo para microrganismos patogênicos para humanos [8].

$\mathrm{O}$ uso de agentes físicos e químicos durante o processo de lavagem constitui uma solução crítica para a redução ou eliminação do risco de contaminação da casca. Compostos de amônio quaternário, carbonato de sódio, hipoclorito de sódio e EDTA já foram testados para utilização em soluções de lavagem devido a sua atividade antimicrobiana em ovos. Entretanto, alguns desses produtos podem alterar a fina e delicada cutícula da casca e, assim, permitir a recontaminação do ovo [8].

FAVIER et al. [8] testaram diferentes produtos para descontaminação de ovos artificialmente contaminados. Os autores utilizaram solução de Extran a 18,75\%, Tergitol tipo 8 a $0,1 \%$, solução de hipoclorito de sódio a 100 ppm e solução de hipoclorito de sódio $100 \mathrm{ppm}+$ Tergitol tipo 8 a $0,1 \%$. Cada grupo de ovos foi lavado por 
imersão durante 5-10 minutos em temperatura ambiente. Para os ovos não inoculados lavados com Extran, hipoclorito de sódio e Tergitol + hipoclorito de sódio a população de bactérias aeróbias foi pouco menor que no caso dos ovos não lavados, porém, sem diferença estatística. Estes resultados são semelhantes aos encontrados no presente estudo. Por outro lado, foi observada por KUO, RICKIE \& CAREY [1 1] uma redução > 3,5 log utilizando solução de 200ppm de hipoclorito de sódio.

WANG \& SLAVIK [23] também observaram a eficiência dos compostos de cloro. Segundo eles, soluções com 100 ppm de cloro livre e compostos de amônio quaternário resultaram na eliminação de microrganismos em ovos, sem danos à cutícula.

OLIVEIRA \& SILVA [16] avaliaram a eficiência de duas soluções desinfetantes em ovos artificialmente contaminados com Salmonella Enteritidis, uma contendo 400ppm de compostos de amônio quaternário e outra contendo 50,2ppm de cloro residual livre. A solução contendo amônio quaternário foi mais eficiente que o composto clorado na redução da contaminação por Salmonella Enteritidis e por mesófilos totais da casca dos ovos. Ambos os desinfetantes foram eficazes na redução, mas não na eliminação total dos contaminantes da casca.

MUSGROVE et al. [14] avaliaram a população de enterobacteriáceas em ovos lavados e não lavados e observaram que os ovos lavados apresentaram uma diminuição significativa destes microrganismos em relação aos ovos não lavados, durante todo o período de amostragem (6 semanas).

Uma vez que o propósito da sanitização é reduzir as populações bacterianas na superficie, e não tornar o ovo isento de microrganismos, a prática da sanitização não precisa, segundo MUSGROVE et al. [15], ser tão rigorosa nas plantas processadoras de ovos, principalmente quando o produto ainda passará por processo de pasteurização.

Neste estudo verificou-se que a pasteurização foi eficiente na inativação de Salmonella e na redução da população de microrganismos aeróbios mesófilos, independente do emprego ou não da lavagem pré-quebra.

DIAS, AJZENTAL \& CALIL [7] avaliaram a microbiota pré e pós-pasteurização do ovo integral líquido e observaram que houve diminuição, e até eliminação, em alguns casos, de microrganismos mesófilos, coliformes totais e fecais e bolores e leveduras após a pasteurização.

\section{4 - CONCLUSÕES}

Baseando-se nos resultados obtidos pode-se concluir que o emprego, ou não, da etapa de lavagem anteriormente à quebra do ovo que será submetido à pasteurização não tem influência na qualidade microbiológica do produto final, desde que a matéria-prima apresente boa qualidade.

\section{5 - REFERÊNCIAS BIBLIOGRÁFICAS}

[1] ANDREWS, W.H.; HAMMACK, T.S. Salmonella (Chapter 5). In: Bacteriological Analytical Manual Online: April 2003.

Disponivel: <http://www.cfsan.fda.gov/ ebam/bam5.html>. Acesso em : 05/02/2005.

[2] ANON. Folder Egg The Dream Ingredient! Food Technol., v.52, 1998.

[3] BARON, F.; BRIANDET, R.; LESNE, J.; HUMBERT, F.; ABLAIN, W.; GAUTIER, M. Influence of a nonfavorable environment, egg white, on resistance to heat and desinfectant, adhesion, and virulence of Salmonella Enteritidis. J. Food Prot., v.67, n.10, p.2269-2273, 2004.

[4] BENNETT, R.W.; LANCETTE, G.A. Staphylococcus aureus (Chapter 12). In: Bacteriological Analytical Manual Online, January 2001.

Disponivel: <http://www.cfsan.fda.gov/ ebam/bam12.html>. Acesso em : 05/02/2005.

[5] BRASIL. Ministério da Agricultura, Pecuária e Abastecimento.

Disponivel: <http://www.agricultura.gov.br>. Acesso em: $23 / 01 / 2005$.

[6] BRASIL. Ministério da Agricultura, Pecuária e Abastecimento (MAPA). Normas gerais de inspeção de ovos e derivados. Secretaria de Inspeção de Produto Animal: Brasilia, 1991. Disponivel:

http://oc4j.agricultura.gov.br/agrolegis/do/consultaLe i ? op =viewTextual\&codigo=5594. Acesso em: 23/01/2005.

[7] DIAS, A.P.; AJZENTAL, A.; CALIL, R.M. Avaliação da microbiota pré e pós-pasteurização do ovo integral liquido. Hig. Aliment., v. 16, n.100, p.127-133. 2002.

[8] FAVIER, G.I.; ESCUDIERO, M.E.; VELÁZQUEZ, L.; GUZMAN, A.M.S. Reduction of Yersinia enterocolitica and mesophilic aerobic bacteria in egg-shell by washing with surfactants and their effect on the shell microstructure. Food Microbiol., v.17, p.73-81, 2000.

[9] HUTCHISON, M.L.; GITTINS, J.; WALKER, A.; SPARKS, N.; HUMPHREY, T.J.; BURTON, C.; MOORE, A. An assessment of the microbiological risks involved with egg washing under commercial conditions. J. Food Prot., v.67, p.4-11, 2004

[10] JONES, D.R.; MUSGROVE, M.T.; NORTHCUTT, J.K. Variations in external and internal microbial populations in shell eggs during extended storage. J. Food Prot., v.67, n.12, p.2657-2660, 2004.

[11] KUO, F.L.; RICKE, S.C.; CAREY, J.B. Shell egg sanitation: UV radiation end egg rotation to effectively reduce populations of aerobes, yeasts, and molds. J. Food Prot., v.60, p.694-697, 1997.

[12] MINTZ, M.L. Dose-responce effects in a outbreak of Salmonella Enteritidis. Epidemiol. Infect., v.112, p.1323, 1994.

[13] MORTON, R.D. Listeria. In: VANDERZANT, C., SPLITTSTOESSER, F. Com pendium of methods for the microbiological examination of foods. Washington: Edward Brothers, 2001. p. 63-67.

[14] MUSGROVE, M.T.; JONES, D.R.; NORTHCUTT, J.K., 
COX, N.A.; HARRISON, M.A. Identification of Enterobacteriaceae from washed and unwashed commercial shell eggs. J. Food Prot., v.67, n.11, p.28012804, 2004.

[15] MUSGROVE, M.T.; JONES, D.R.; NORTHCUTT, J.K.; CURTIS, P.A.; ANDERSON, K.E.; FLETCHER, D.L.; COX, N.A. Survey of shell egg processing plant sanitation programs: effects on non-egg-contact surfaces. J. Food Prot., v.67, n.12, p.2613-2616, 2004.

[16] OLIVEIRA, D.D. E SILVA, E.N. Salmonella em ovos comerciais: ocorrência, condições de armazenamento e desinfecção da casca. Arq. Bras. Med. Vet. Zootec., v.52, n.6, p.655-661, 2000.

[17] PAGANO, M. e GRAVEAU, K. Princípios de Bioestatística, Ed. Thomson, 2ed, 2004.

[18] PAGOTTO, F.; DALEY, E.; FARBER, J.M. Enumeration of Listeria monocytogenes in foods. In: Health Products and Food Branch. Food Directorates (Health Canada). Ottawa: 2002. Disponivel: http://www.hcsc.gc.ca/food-aliment. Acesso em: 05/02/2005.

[19] REU, K.; GRIJSPEERDT, K.; HEYNDRICKX, M.; UYTTENDAELE, M.; HERMAN, L. The use of total aerobic and Gram-negative flora for quality assurance in the production chain of consumption eggs. Food Control, v.16, p.147-155, 2005.

[20] RICKE, S.C.; BIRKHOLD, S.G.; GAST. R.K. Eggs and Egg Products. In: Compendium of Methods for the Microbiological Examination of Foods, 4 ed. Washington: American Public Health Association (APHA), 2001. p.473-481.

[21] RODRIGUES, K.R.M. E SALAY, E. Atitudes de granjeiros, atacadistas, varejistas e consumidores em relação à qualidade sanitária do ovo de galinha in natura. Rev. Nutr., v. 14, n.3, p.185-193, 2001.

[22] SCHOENI, J. L.; GLASS, K.A.; MCDERMOTT, J.L.; WONG, A.C.L. Growth and penetration of Salmonella enteritidis, Salmonella heidelberg and Salmonella typhimurium in eggs. Int. J. Food Microbiol., v.24, p.385396, 1995.

[23] WANG, H. E SLAVIK, M.F. Bacterial penetration into eggs washed with various chemicals and stored at different temperatures and times. J. Food Prot., v.61, p.276-279, 1998. 